\title{
Atmospheric torques and Earth's rotation: what drove the millisecond-level length-of-day response to the 2015-2016 El Niño?
}

\author{
Sébastien B. Lambert ${ }^{1}$, Steven L. Marcus ${ }^{2}$, and Olivier de Viron ${ }^{3}$ \\ ${ }^{1}$ SYRTE, Observatoire de Paris, PSL Research University, CNRS, \\ Sorbonne Universités, UPMC Univ. Paris 06, LNE, Paris, France \\ ${ }^{2}$ Independent Researcher, Santa Monica, California, USA \\ ${ }^{3}$ Littoral, Environnement et Sociétés (LIENSs), Université de \\ La Rochelle and CNRS - UMR7266, La Rochelle, France \\ Correspondence to: Sébastien B. Lambert (sebastien.lambert@obspm.fr) \\ Received: 30 May 2017 - Discussion started: 18 July 2017 \\ Revised: 11 October 2017 - Accepted: 11 October 2017 - Published: 14 November 2017
}

\begin{abstract}
El Niño-Southern Oscillation (ENSO) events are classically associated with a significant increase in the length of day (LOD), with positive mountain torques arising from an east-west pressure dipole in the Pacific driving a rise of atmospheric angular momentum (AAM) and consequent slowing of the Earth's rotation. The large 1982-1983 event produced a lengthening of the day of about $0.9 \mathrm{~ms}$, while a major ENSO event during the 2015-2016 winter season produced an LOD excursion reaching $0.81 \mathrm{~ms}$ in January 2016. By evaluating the anomaly in mountain and friction torques, we found that (i) as a mixed eastern-central Pacific event, the 20152016 mountain torque was smaller than for the 1982-1983 and 1997-1998 events, which were pure eastern Pacific events, and (ii) the smaller mountain torque was compensated for by positive friction torques arising from an enhanced Hadley-type circulation in the eastern Pacific, leading to similar AAM-LOD signatures for all three extreme ENSO events. The 2015-2016 event thus contradicts the existing paradigm that mountain torques cause the Earth rotation response for extreme El Niño events.
\end{abstract}

Copyright statement. All the authors have agreed to the licence and copyright agreement.

\section{Introduction}

Earth rotation fluctuates with time, as a response to the interaction of the solid Earth with celestial bodies, the liquid core, and the fluid layers of the climate system. This interaction results in changes of the orientation of the Earth rotation vector in space, of the orientation of the Earth around its rotation axis, and of the Earth rotation angular velocity associated with changes in the length of the day (LOD). Variations in the LOD can reach a few milliseconds on the timescale of a few tens of years, due to core-mantle interaction (Holme and de Viron, 2013, and references therein), and a few tenths of a millisecond on the timescale of some days to several years, due mostly to solid-Earth-atmosphere interaction (Hide and Dickey, 1991), though the solid-Earthocean interaction does play a small role (Marcus et al., 1998, 2012; Dickey et al., 2010). A major atmospheric impact on Earth rotation occurs on the annual timescale (Hide et al., 1998), due to the hemispheric asymmetry of the seasonal cycle (de Viron et al., 2002), with El Niño-Southern Oscillation (ENSO) events (Chao, 1984; Carter et al., 1984) dominating interannual (2-7 year) variability.

Extreme El Niño events such as those that occurred in the winters of 1982-1983, 1997-1998 and 2015-2016 (e.g., http: //ggweather.com/enso/oni.htm), can generate LOD anomalies reaching amplitudes of nearly a millisecond with respect to the climatological seasonal cycle. Previous studies 
found that the creation of the large LOD anomaly during the 1982-1983 event was mainly due to mountain torque on the American and Eurasian orography (Ponte et al., 1994; Ponte and Rosen, 1999). In general, the paradigm has emerged that mountain torques (defined more precisely below) generate the rotational anomalies associated with the El Niño cycle, while friction torques play a more passive role by damping these anomalies back towards their climatological norms.

Considering two types of El Niño events defined in the recent literature (see below), de Viron and Dickey (2014) showed that central Pacific (CP) events are associated with smaller LOD anomalies than eastern Pacific (EP) events, due to the position and amplitude of the pressure anomaly over the Pacific Ocean that generates a weaker mountain torque. While 1982-1983 and 1997-1998 are cited as examples of classical EP events, Paek et al. (2017) noted the different nature of the extreme 2015-2016 episode, finding it to be the strongest mixed EP-CP event ever recorded. In this paper we seek to document and understand how the different atmospheric torques active during the recent mixed event raised the atmospheric angular momentum (AAM) and consequently the LOD anomalies to values similar to those reached during the previous extreme EP events. As an extreme event of a unique nature, the 2015-2016 mixed EPCP episode offers a chance to gain further insights into how atmospheric dynamics link Earth rotation anomalies to different types of El Niño (Johnson, 2013).

\section{Methods and data}

When studying the impact of the atmosphere on Earth rotation, two different approaches can be used. First, one can consider that the atmosphere is included in the Earth system, compute the variation of the AAM, consider that the angular momentum of the system is conserved - that what is lost by the atmosphere is gained by the solid Earth - and estimate from there the Earth rotation change: this is known as the angular momentum approach. The other approach considers the atmosphere as an external forcing on the solid Earth, computes the torque exerted by the atmosphere on the solid Earth, and estimates the Earth rotation changes using the angular momentum budget equation. Note that the angular momentum approach (applied below in Fig. 2) is preferred for explicating (or predicting) LOD anomalies, which can serve as external "ground truth" for validating model-specified (or predicted) AAM under the severe conditions associated with extreme ENSO episodes. Conversely, the torque approach (applied below in Fig. 4) can provide dynamical insight into the mechanisms generating the near-millisecond LOD anomalies that accompany these events and can also be used for internal consistency checks of the model AAM budgets under the strong perturbations involved.

As shown in Barnes et al. (1983), the total torque exerted by the atmosphere on the Earth is composed of three effects: the gravitational attraction of the mass anomalies inside the Earth by those inside the atmosphere, the atmospheric pressure acting over the topography, and the friction of the wind on the surface. The first two contributions are classically merged into the so-called mountain torque while the latter is known as friction torque.

We used standard formulations of the AAM, and mountain and friction torques that can be found in Huang et al. (1999), for example. The AAM is composed of two parts, a mass term corresponding to the angular momentum associated with the rigid rotation of the atmosphere with the solid Earth and a motion term corresponding to the relative angular momentum of the atmosphere with respect to the solid Earth. The $Z$ component of the AAM was estimated from

$$
\begin{aligned}
& H_{Z}^{\text {mass }}=\frac{a^{4} \Omega}{g} \int_{0}^{2 \pi} \int_{0}^{\pi} P_{\mathrm{s}} \sin ^{3} \theta \mathrm{d} \theta \mathrm{d} \lambda, \\
& H_{Z}^{\text {motion }}=\frac{a^{3}}{g} \int_{0}^{2 \pi} \int_{0}^{\pi} \int_{0}^{P_{\mathrm{s}}} u \sin ^{2} \theta \mathrm{d} p \mathrm{~d} \theta \mathrm{d} \lambda,
\end{aligned}
$$

where $a$ is the mean Earth radius, $g$ is the mean gravity acceleration, $u$ is the zonal wind, $P_{\mathrm{s}}$ is the surface pressure, $\theta$ and $\lambda$ are the colatitude and longitude, respectively, and $\Omega$ is the Earth mean angular velocity. The axial torques were estimated using

$$
\begin{aligned}
& \Gamma_{Z}^{\text {mountain }}=a^{3} \int_{0}^{2 \pi} \int_{0}^{\pi} \frac{\partial P_{\mathrm{s}}}{\partial \lambda} h \sin \theta \mathrm{d} \theta \mathrm{d} \lambda, \\
& \Gamma_{Z}^{\text {friction }}=-a^{3} \int_{0}^{2 \pi} \int_{0}^{\pi} \tau_{\lambda} \sin ^{2} \theta \mathrm{d} \theta \mathrm{d} \lambda,
\end{aligned}
$$

where $h$ is the orography and $\tau_{\lambda}$ is the zonal friction drag. The time rate of change of the total AAM is given by the sum of the mountain and friction torques (e.g., Barnes et al., 1983):

$$
\frac{\mathrm{d}}{\mathrm{d} t}\left(H_{Z}^{\text {mass }}+H_{Z}^{\text {motion }}\right)=\Gamma_{Z}^{\text {mountain }}+\Gamma_{Z}^{\text {friction }} .
$$

In what follows, the time-integrated form of Eq. (5) was used to evaluate the sources of AAM maxima associated with recent extreme El Niño events. Given the AAM variation, the induced change in the LOD is estimated by

$$
\frac{\Delta \mathrm{LOD}}{\overline{\mathrm{LOD}}}=\frac{\Delta\left(0.7 H_{Z}^{\mathrm{mass}}+H_{Z}^{\text {motion }}\right)}{C \Omega},
$$

where $\overline{\mathrm{LOD}}$ is the nominal length of the solar day (86400s) and $C$ is the axial mean moment of inertia of the Earth; the mass term is evaluated using the inverted barometer assumption (Jeffreys, 1916) to account for the quasi-static response 
of the oceans to atmospheric pressure loading, and the factor of 0.7 accounts for the compensating changes in the moment of inertia arising from the elastic deformation of the solid Earth in response to the surface loading (Munk and MacDonald, 1960; Barnes et al., 1983).

Our computations of AAM and torques were based on $2^{\circ} \times 2^{\circ}$ surface pressure, zonal momentum flux, and zonal wind speed data from daily and monthly values from the European Center for Medium-range Weather Forecasts (ECMWF) ERA-Interim model (Dee et al., 2011) spanning 1979-2017. Wind speeds were taken at 17 pressure levels between 10 and $1000 \mathrm{hPa}$. The longitudinal gradients of the pressure field were computed with a five-point stencil.

For computation of the mountain torque, we used the model orography at its native $2^{\circ} \times 2^{\circ}$ resolution, thereby ensuring consistency between the wind, pressure, and zonal momentum flux data sets and the derived AAM and torque quantities. A recent study by van Niekerk et al. (2016) found that resolved mountain torques in the Met Office United Model with free atmospheric wind and temperature relaxed to ERA-Interim reanalyses are relatively insensitive to increasing model resolution (see, e.g., their Fig. 7), although they are more strongly impacted by large-scale (synoptic) processes than are the parameterized sub-grid scale torques (not considered in our study).

Earth rotation data were provided by the International Earth Rotation And Reference Systems Service (IERS) Earth Orientation Parameters (EOP) 14 C04 series available via the IERS Earth Orientation Centre website (http://iers.obspm.fr/ eop-pc). This combination of very-long-baseline interferometry (VLBI), global navigation satellite systems (GNSSs), Doppler Orbitography and Radiopositioning Integrated by Satellite (DORIS), and satellite laser ranging (SLR) data provides daily estimates of the LOD with an accuracy of about $0.05 \mathrm{~ms}$. To isolate the anomalous changes due to episodic events like ENSO as much as possible, we subtracted modeled zonal tides (Petit and Luzum, 2010), a multidecadal trend estimated with a 4-year running mean and a 5.9-year periodic term - attributed to secular tidal braking and postglacial rebound (Hide and Dickey, 1991) and variations in the fluid core angular momentum (Hide et al., 2000; Holme and de Viron, 2013) - and a mean seasonal cycle estimated over 1979-2017. The residual LOD contains essentially the fluctuation associated with anomalous AAM and oceanic currents, with the latter being less than $5 \%$.

As measurements of ENSO activity, we used monthly series of Niño $1+2$, Niño 3 , Niño 4 , and Niño 3.4 indices retrieved from the Climate Prediction Center (CPC) of NOAA. We used the Niño $1+2$, Niño 3, and Niño 4 series to compute the indices relevant to EP and $\mathrm{CP}$ events considered in Takahashi et al. (2011, their Eqs. 3 and 4) and Ren and Jin (2011, their Eq. 1). For comparison, we also used corresponding EP-CP indices provided by Kao and Yu (2009) at https://www.ess.uci.edu/ yu/2OSC and the $\mathrm{PT}^{\prime}$ indices of Chen and Wallace (2016, private communication).
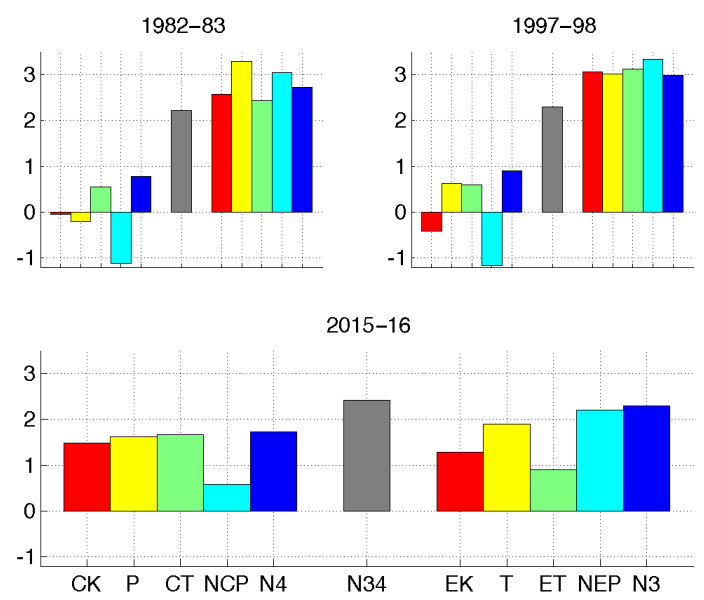

Figure 1. The December-February Niño 3.4 (N34), Niño 3 (N3), and Niño 4 (N4) indices and other various eastern and central $\mathrm{Pa}-$ cific projection indices for each of the three events. Eastern (central) Pacific indices are represented right (left) of the Niño 3.4 bar. EK and CK: E and C indices from Kao and Yu (2009); P and T: P and $\mathrm{T}^{\prime}$ indices from Chen and Wallace (2016); ET and CT: E and C indices from Takahashi et al. (2011); NEP and NCP: eastern Pacific and central Pacific indices as defined by Ren and Jin (2011).

We removed seasonal composites and linear trends from all grids and time series and we formed 2-month "winter" values of all the time-variable quantities above preceding the respective AAM-LOD maxima, by averaging over December-January for the EP events and over NovemberDecember for the mixed EP-CP event (see below). For computation of regional torques, we used a modified version of the land-sea masks, whose geographical limits can be seen in Fig. 3 of Marcus et al. (2011), with limits of the equatorial zone set to $\pm 15^{\circ}$ from the Equator. Moreover, we separated Greenland from North America and the Pacific Ocean into eastern and western zones, respectively, east and west from the International Date Line.

\section{Analysis and results}

For the three extreme El Niño events that occurred in the last 40 years (winters of 1982-1983, 1997-1998, and 20152016), the Niño 3.4 index reached values of more than 2 times its standard deviation over the winter season. A feature that makes the 2015-2016 ENSO event unique is the hybrid aspect mentioned by Paek et al. (2017), who showed that EP$\mathrm{CP}$ indices defined by Kao and Yu (2009) were of comparable magnitudes, in contrast to their highly positive EP index and small or negative CP index in 1997-1998. Similar conclusions can be drawn on the basis of projections provided by Takahashi et al. (2011) and Ren and Jin (2011), the former seeing the 2015-2016 event as more of a CP and the latter as more of an EP type (Fig. 1). Chen and Wallace (2016), who considered a methodology similar to Takahashi et al. 
(2011) but also considering extratropical Pacific variability, derived indices of equal magnitudes by including contributions of higher-latitude sea surface temperature (SST).

For the three events, anomalous LOD excursions reached the level of nearly a millisecond, consistent with the AAM variation (Fig. 2). The Niño 3.4 index reached its maximum values between 1 and 3 months before AAM and LOD (Dickey et al., 2007). Differences between AAM and LOD anomalies might be partly due to a small, variable contribution from the ocean and hydrology and to local biases or side effects induced by the filtering and smoothing method used to separate the nonseasonal LOD from its multidecadal and interannual trends. We found that the LOD for the 20152016 event peaked at $0.81 \mathrm{~ms}$ on 6 January 2016. Figure 2 also suggests that the 1982-1983 event was the strongest from the Earth rotation point of view, generating an LOD anomaly of $0.91 \mathrm{~ms}$, which is about 3.5 times the standard deviation of the mean seasonal cycle. The 1997-1998 event was somewhat less active with an LOD anomaly of only $0.76 \mathrm{~ms}$. Our values are consistent with analyses of Gipson (2016), who found comparable excursions of the LOD in 1997-1998 and 2015-2016 of about $0.75 \mathrm{~ms}$, based on VLBI data; interestingly, however, the maximum rotational anomalies for the two earlier EP events occur nearly a month later in the season than for the 2015 mixed event.

In order to analyze the synoptic features giving rise to these rotational anomalies, we formed global maps of the surface pressure and surface friction drag anomalies for the 2 months that preceded them, averaging over DecemberJanuary for the 1982-1983 and 1997-1998 winters and over November-December for the 2015-2016 winter (Fig. 3). The two EP surface pressure maps (1982-1983 and 1997-1998) reveal the classic east-west dipole for this type of event noted by de Viron and Dickey (2014), with the low-pressure areas in proximity to the American coast generating substantial positive mountain torques on the atmosphere and thereby increasing the LOD. For the mixed EP-CP event in 2015, however, the surface pressure gradients have a substantial meridional component, with a low-pressure area in the equatorial east-central Pacific flanked by anomalous high-pressure zones in the northeastern (NE) and southeastern (SE) Pacific. This Hadley-type pattern gives rise to anomalous easterlies in the eastern equatorial (EE) Pacific, generated as inflow to the equatorial low-pressure area near $120^{\circ} \mathrm{W}$, and also in the NE and SE Pacific, generated as enhanced easterly flow on the equatorward flanks of the anomalous high-pressure Pacific areas. The result is a significant enhancement of positive friction torque over the eastern tropical and midlatitude Pacific, denoted by the orange shaded areas in the right-hand column of Fig. 3, for the mixed EP-CP event as compared with the earlier EP events. This comparison is highlighted in panels ( $g$ and $h$ ) of Fig. 3, which show the difference of the surface pressure and friction drag anomalies between the 2-month means for the mixed event and the average of the two EP events. The pressure difference (Fig. 3g) shows that

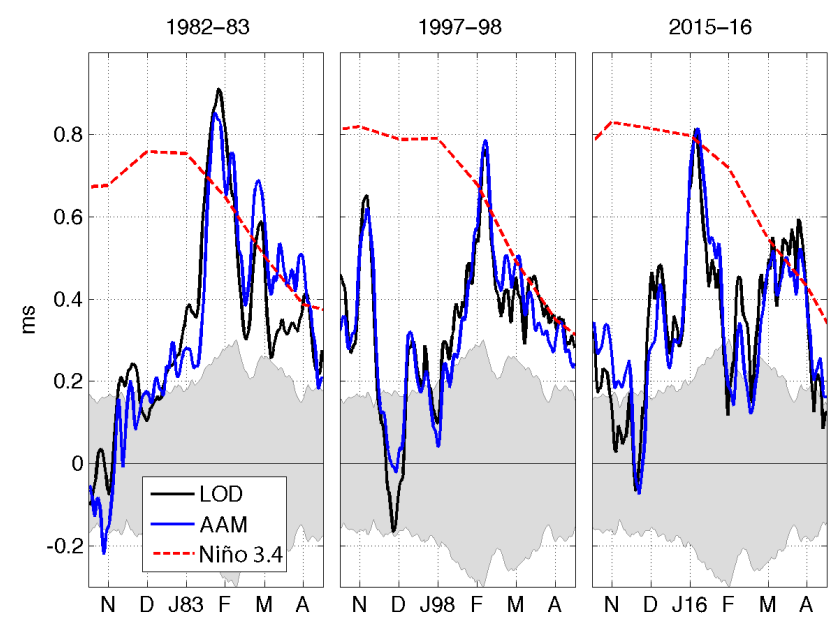

Figure 2. The time series of daily AAM (blue) and LOD (black) values around the three extreme events. The red dashed line represents the scaled monthly Niño 3.4 index. The shaded area represents 1 standard deviation around the climatological mean. The $x$-axis ticks indicate the first day of each month.

the change between the mixed and EP events takes the form of a strengthened Hadley-type circulation in the east-central Pacific, with the stronger and more equatorward response in the winter (northern) hemisphere. This is reflected in the friction difference between the mixed and EP events (Fig. 3h), which shows a strong enhancement of the surface drag in the NE Pacific and the EE Pacific; a weaker enhancement is also seen over the midlatitude SE Pacific, compensated for by enhanced westerlies over the Antarctic Circumpolar Current.

The main features observed in the maps are reflected by the values of the 2-month averaged mountain and friction torque anomalies for the various land and ocean areas given in Table 1. The lower net 2015-2016 mountain torque compared to $1982-1983$ and $1997-1998$ is consistent with the lack of a pronounced east-west pressure dipole in the $\mathrm{Pa}$ cific in late 2015, resulting in a substantial negative torque over North America and Greenland during that time, while the low-pressure anomaly in the equatorial Pacific generated similar positive mountain torques over South America as for the EP events. A significant portion of the remaining difference in global mountain torque between the three events is generated over the European continent, as a consequence of changes in the relative positions of large-scale North Atlantic features during the winter, possibly influenced by El Niño (Butler et al., 2014), that modify the direction and the intensity of the downstream pressure gradients over the continental orography (particularly the Caucasus and Zagros mountains). The lack of a net positive mountain torque leading up to the 2015-2016 rotational maximum, however, is compensated for by the presence of positive friction torques during that time, particularly over the eastern Pacific, with the $\mathrm{NE}$ and $\mathrm{EE}$ regions making the largest contributions, relative 

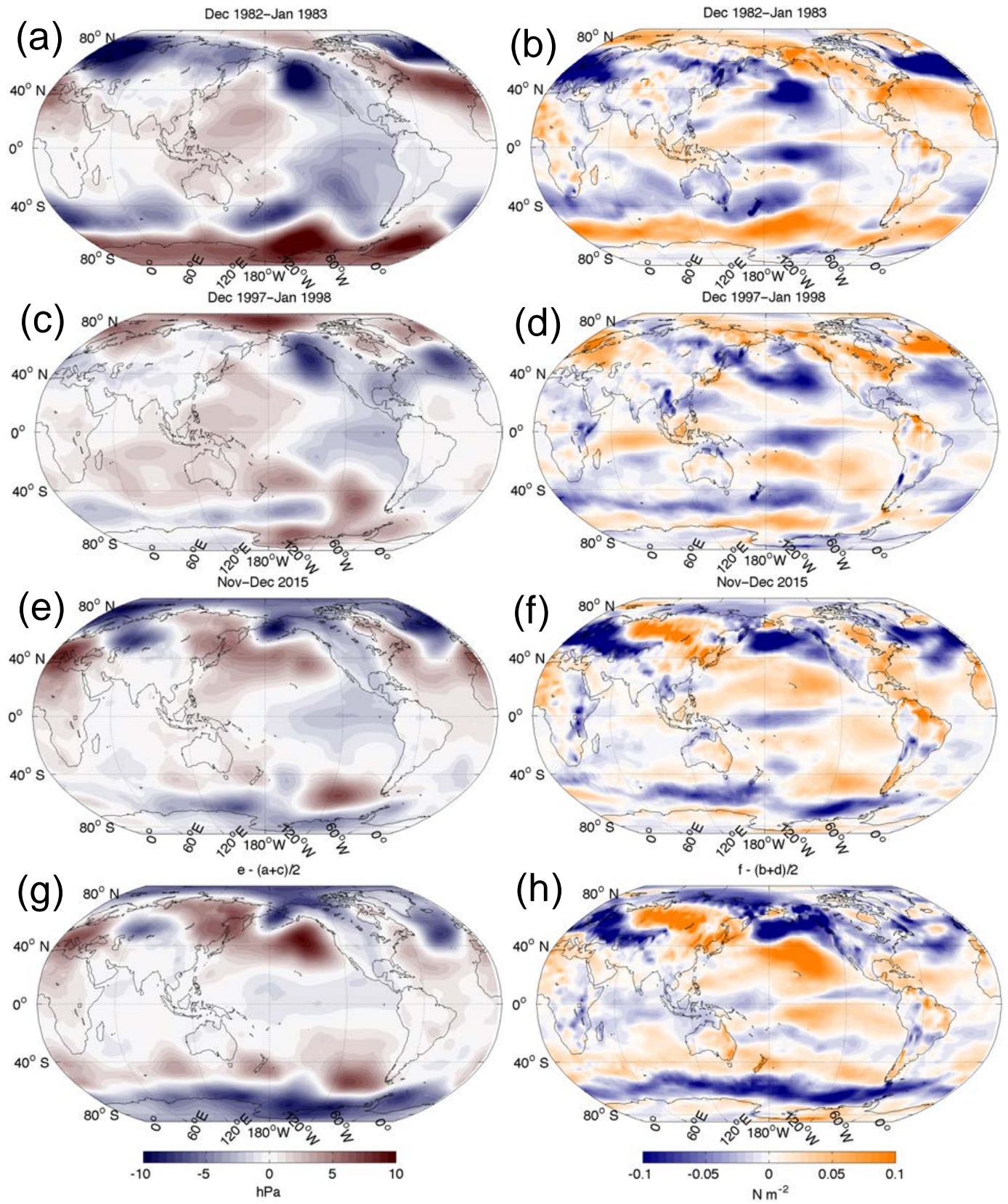

Figure 3. (a, c, e) The surface pressure and (b, d, f) zonal friction drag anomalies averaged over December-January for the 1982-1983 and 1997-1998 EP events and averaged over November-December for the 2015-2016 EP-CP event. Panels (g) and (h) show, respectively, the difference in pressure and zonal friction drag anomaly between the 2015-2016 situation and the average of the 1982-1983 and 1997-1998 situations.

to their corresponding values during the EP events; the intense high-pressure area in the SE Pacific, reminiscent of the November 2009 feature discussed by Lee et al. (2010), makes a smaller positive contribution to the CP-EP axial torque difference due to its higher latitude.

The contributions of these processes to the LOD maxima generated during the three extreme events can be illustrated by integrating the daily torques over preceding intervals in the time domain to reconstitute the AAM. The difference between the integrated friction and mountain torques and the AAM arising from gravity-wave drag and other torques related to the sub-grid-scale orography is generally considered to be negligible on these timescales (de Viron et al., 1999; Ponte and Rosen, 1999). As starting epochs, we chose the beginning of the rise of each AAM curve towards its peak value. The resulting reconstituted AAM components - con- 
Table 1. Contributions to the mountain and friction torques exerted by the solid Earth onto the atmosphere in Hadley (i.e., $10^{18} \mathrm{Nm}$ ), averaged over December-January for the 1982-1983 and 19971998 EP events (columns D82-J83 and D97-J98, respectively) and averaged over November-December for the 2015-2016 EP-CP event (column ND15).

\begin{tabular}{|c|c|c|c|}
\hline & D82-J83 & D97-J98 & ND15 \\
\hline \multicolumn{4}{|c|}{ Mountain torque } \\
\hline Global & 3.8 & 10.4 & -0.0 \\
\hline Africa & 0.1 & 1.6 & -1.1 \\
\hline Europe & -3.3 & 0.7 & -2.7 \\
\hline Greenland & -3.8 & 2.1 & -2.5 \\
\hline North America & 4.6 & 0.6 & -0.8 \\
\hline South America & 6.6 & 6.0 & 6.1 \\
\hline Asia & 1.8 & 1.2 & 3.3 \\
\hline Oceania & -0.4 & -0.1 & 0.2 \\
\hline Antarctica & 0.0 & -0.2 & -1.1 \\
\hline \multicolumn{4}{|c|}{ Friction torque } \\
\hline Global & 0.7 & -2.0 & 4.6 \\
\hline Africa & 2.8 & -0.5 & 1.9 \\
\hline Europe & -2.9 & 1.2 & -2.6 \\
\hline Greenland & -0.0 & 0.1 & -0.0 \\
\hline North America & 2.3 & 2.0 & 0.7 \\
\hline South America & 1.6 & 0.8 & 1.2 \\
\hline Asia & -0.4 & -0.6 & 1.2 \\
\hline Oceania & -0.7 & 0.2 & 0.2 \\
\hline Antarctica & 0.1 & -0.1 & 0.1 \\
\hline NE Pacific & -4.1 & -3.2 & 0.3 \\
\hline NW Pacific & -0.3 & -1.0 & 0.8 \\
\hline EE Pacific & -2.3 & -2.0 & 0.3 \\
\hline EW Pacific & 1.4 & -0.0 & -0.3 \\
\hline SE Pacific & 1.4 & 2.3 & 2.7 \\
\hline SW Pacific & -0.7 & -0.4 & -0.4 \\
\hline North Atlantic & 1.9 & -1.8 & -0.2 \\
\hline Eq. Atlantic & 0.5 & -0.2 & 0.2 \\
\hline South Atlantic & -0.0 & -0.7 & -0.5 \\
\hline Indian Ocean & -0.6 & 0.5 & -0.7 \\
\hline Antarctic Ocean & 1.1 & 0.8 & -0.5 \\
\hline
\end{tabular}

sistent with Figs. 2 and 3 of Ponte and Rosen (1999) for the 1982-1983 event - are shown in Fig. 4. They reveal that a positive friction episode occurred in 2015-2016 about 15 to 20 days before the AAM peak. Such a positive friction episode, occurring about 10 to 15 days before the AAM peak, was totally absent from the 1997-1998 event and was much smaller in the 1982-1983 event, when the integrated friction torque remains positive during a few days before turning back to negative values. Note that choosing starting epochs and an integration period consistent with the 2-month intervals considered above leads to similar conclusions but to less consistent closures of the budget due to small biases accumulated in the integration, as already mentioned in Ponte and Rosen (1999). The lower panel of Fig. 4 demonstrates the im-
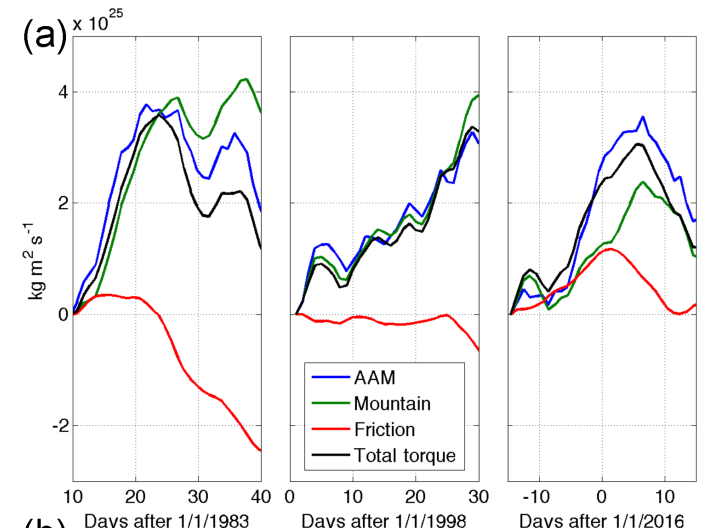

(b) Days after 1/1/1983 Days after 1/1/1998 Days after 1/1/2016

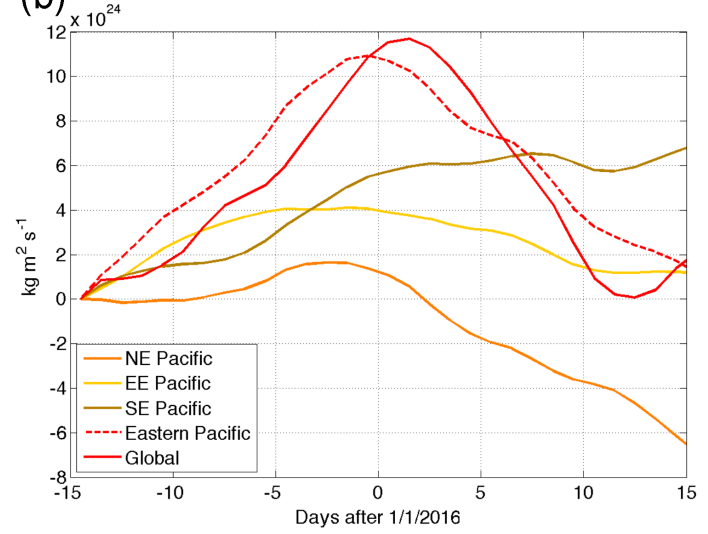

Figure 4. (a) The integrated torques compared to AAM during the three events and (b) the integrated friction torque with contribution from the different regions of the Pacific Ocean during the 20152016 event.

portance of the eastern Pacific contribution to the overall positive friction torque in the last 2 weeks of 2015 and highlights absolute contributions from the EE and SE Pacific regions at this time. The NE Pacific also contributes positively but to a lesser extent; its contribution relative to the corresponding (negative) NE Pacific values for the EP events, however, is greater than those for the EE and SE regions combined over the 2 months preceding these events (Table 1). A Hovmöller (time-latitude) plot of the eastern Pacific frictional drag contributing to the 2015-2016 LOD maximum (Fig. 5) highlights its three-belt structure and shows the EE Pacific contribution (spanning $15^{\circ} \mathrm{N}-15^{\circ} \mathrm{S}$ ) to arise from two areas: one in the Southern Hemisphere originating from inflow to the westwardly displaced boreal winter Hadley circulation and one in the Northern Hemisphere originating from enhanced easterly flow on the equatorward flank of the NE Pacific high-pressure area (similar to the November-December 2015 pressure anomalies seen in Fig. 3e). 


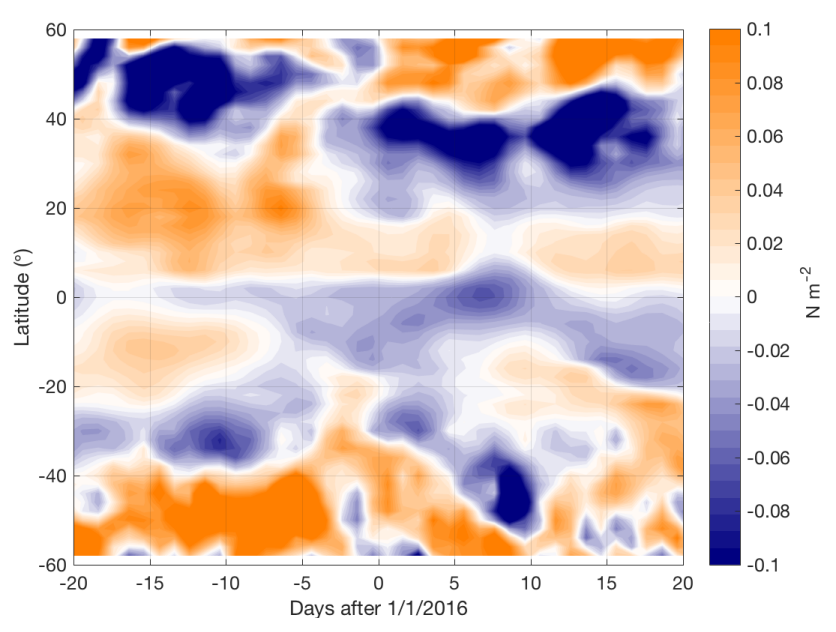

Figure 5. Time-latitude (Hovmöller) diagram of the zonal friction drag anomaly between 11 December 2015 and 20 January 2016 and averaged over longitudes between 180 and $270^{\circ}$.

\section{Discussion and conclusion}

Surface pressure and friction torque anomaly maps for the last 2 months before each extreme AAM-LOD peak (Fig. 3) and a time-latitude plot of frictional stress during the last event (Fig. 5) suggest that the 2015-2016 positive friction torque arose from three zones: in the NE Pacific between latitudes of 0 and $40^{\circ} \mathrm{N}$, in the EE Pacific off Peru, and in the SE Pacific between 40 and $60^{\circ} \mathrm{S}$, showing rough symmetry about an enhanced (boreal winter) Hadley-type circulation in the east-central Pacific. The positive (LOD-lengthening) EE Pacific contribution to the friction torque can be understood in the context of a CP event in which the ENSO-driven convection is displaced towards the central Pacific; the incoming winds that supply the convection are westward in the EE Pacific. From the momentum point of view, this convection also strengthens the Hadley circulation and the subtropical jets that carry the bulk of the AAM signal. The SE Pacific positive torque contribution results from a strengthening of the extratropical South Pacific anticyclone similar to that documented in November 2009 during a CP event (Lee et al., 2010), with the NE Pacific positive contribution stemming from a similar high-pressure response in the subtropical winter hemisphere. Note, however, that the weaker 20092010 CP event, which lacked the NE Pacific circulation center found during the extreme 2015-2016 episode, did not produce a significant anomaly in AAM or LOD.

The three extreme ENSO events of 1982-1983, 19971998, and 2015-2016 were of comparable strengths expressed through both SST and subsurface indices (L'Heureux et al., 2017). The latest was, however, of a different nature, as a mixed EP-CP event, as opposed to the other two pure EP events (Paek et al., 2017; Palmeiro et al., 2017). All three events produced anomalous excursions of the Earth's LOD between $0.76 \mathrm{~ms}$ (1997-1998) and $0.91 \mathrm{~ms}$ (1982-1983), the amplitude of the 2015-2016 (0.81 ms) excursion being intermediate. We showed that, though the 1982-1983 and 19971998 LOD anomalies were driven by the mountain torque, as expected with pure EP events, the LOD excitation mechanism of the mixed EP-CP 2015-2016 event was different. The weaker mountain torque was compensated for by a positive friction torque acting in the eastern Pacific, both in an absolute sense and relative to the frictional torques prevailing there during the earlier EP events. The 2015-2016 event, unique for its nature and intensity among the ENSO events recorded for the last 4 decades, thus contradicts the existing paradigm that mountain torques cause the Earth rotation response for extreme El Niño events.

For mixed or $\mathrm{CP}$ events, increasing in frequency and strength since the turn of the century (Wang and Cai, 2013), friction torques arising form tropical and extratropical centers of action can make a significant contribution to the positive LOD anomalies, thereby compensating for the less efficient CP mountain torque coupling (de Viron and Dickey, 2014) and maintaining the capability for a robust rotational response to this new type of event. Interestingly, enhanced easterlies (or positive friction; England et al., 2014), more and stronger CP events (Lee and McPhaden, 2010; Paek et al., 2017), and the global warming hiatus (Douville et al., 2015; Song et al., 2016) have coincided in the early 21 st century; the chain of causality among these events, however, is far from clear.

These three extreme events also exemplify the complex relation between the ENSO strength and the atmospheric response (AAM and torques) that leads to variations in the Earth's rotation rate. The dominant factor is the position and the depth of the ENSO pressure dipole that can significantly strengthen or weaken the mountain torques exerted by the atmosphere on the Andes and the Rocky Mountains. Nevertheless, the factors governing teleconnections between tropical Pacific SST anomalies and the globally distributed pressurewind response that are still being actively investigated (e.g., Ji et al., 2016) may play a critical role in determining the relative rotational signatures of the events.

Data availability. Surface pressure, wind, zonal momentum flux (eastward turbulent surface stress) and orography data used in this study are made publicly available by the European Center for Medium range Weather Forecasts (ECMWF) at http://apps. ecmwf.int/datasets/data/interim-full-daily/levtype $=$ sfc/. The ENSO indices are publicly available via the Climate Prediction Center of the NOAA at http://www.cpc.ncep.noaa.gov/data/indices/ersst4. nino.mth.81-10.ascii. Earth rotation data are available via the IERS Earth Orientation Centre website (http://iers.obspm.fr/eop-pc).

Author contributions. SL proposed the idea for this study. All authors contributed to developing the methods and analyzing the data as well as contributed the materials and analysis tools. All the authors jointly wrote the paper and extensively discussed the re- 
sults and the interpretations. All authors read and approved the final manuscript.

Competing interests. The authors declare that they have no conflict of interest.

Acknowledgements. The work of Olivier de Viron was financially supported by CNES, through the TOSCA program, as an application of the geodesy missions.

Edited by: Valerio Lucarini

Reviewed by: Antonio Speranza and one anonymous referee

\section{References}

Barnes, R. T. H., Hide, R., White, A. A., and Wilson, C. A.: Atmospheric angular momentum fluctuations, length-of-day changes and polar motion, P. Roy. Soc. Lond. A, 387, 31-73, https://doi.org/10.1098/rspa.1983.0050, 1983.

Butler, A. H., Polvani, L. M., and Deser, C.: Separating the stratospheric and tropospheric pathways of El Niño-Southern Oscillation teleconnections, Environ. Res. Lett., 9, 024014, https://doi.org/10.1088/1748-9326/9/2/024014, 2014.

Carter, W., Robertson, D., Pettey, J., Tapley, B., Schutz, B., Eanes, R., and Lufeng, M.: Variations in the rotation of the Earth, Science, 224, 957-961, 1984.

Chao, B. F.: Interannual length-of-day variation with relation to the Southern Oscillation/El Niño, Geophys. Res. Lett., 11, 541-544, 1984.

Chen, X. and Wallace, J. M.: Orthogonal PDO and ENSO Indices, J. Climate, 29, 3883-3892, 2016.

Dee, D. P., Uppala, S. M., Simmons, A. J., Berrisford, P., Poli, P., Kobayashi, S., Andrae, U., Balmaseda, M. A., Balsamo, G., Bauer, P., Bechtold, P., Beljaars, A. C. M., van de Berg, L., Bidlot, J., Bormann, N., Delsol, C., Dragani, R., Fuentes, M., Geer, A. J., Haimberger, L., Healy, S. B., Hersbach, H., Hólm, E. V., Isaksen, L., Kållberg, P., Köhler, M., Matricardi, M., McNally, A. P., Monge-Sanz, B. M., Morcrette, J.-J., Park, B.-K., Peubey, C., de Rosnay, P., Tavolato, C., Thépaut, J.-N., and Vitart, F.: The ERA-Interim reanalysis: configuration and performance of the data assimilation system, Q. J. Roy. Meteorol. Soc., 137, 553597, https://doi.org/10.1002/qj.828, 2011.

de Viron, O. and Dickey, J. O.: The two types of El-Niño and their impacts on the length of day, Geophys. Res. Lett., 41, 34073412, https://doi.org/10.1002/2014GL059948, 2014.

de Viron, O., Bizouard, C., Salstein, D., and Dehant, V.: Atmospheric torque on the Earth and comparison with atmospheric angular momentum variations, J. Geophys. Res.-Solid Ea., 104, 4861-4875, https://doi.org/10.1029/1998JB900063, 1999.

de Viron, O., Dickey, J., and Marcus, S.: Annual atmospheric torques: Processes and regional contributions, Geophys. Res. Lett., 29, 44-1-44-3, 2002.

Dickey, J. O., Marcus, S. L., and Chin, T. M.: Thermal wind forcing and atmospheric angular momentum: Origin of the Earth's delayed response to ENSO, Geophys. Res. Lett., 34, L17803, https://doi.org/10.1029/2007GL030846, 2007.
Dickey, J. O., Marcus, S. L., and de Viron, O.: Closure in the Earth's angular momentum budget observed from subseasonal periods down to four days: No core effects needed, Geophys. Res. Lett., 37, 103307, https://doi.org/10.1029/2009GL041118, 2010.

Douville, H., Voldoire, A., and Geoffroy, O.: The recent global warming hiatus: What is the role of Pacific variability?, Geophys. Res. Lett., 42, 880-888, https://doi.org/10.1002/2014GL062775, 2015.

England, M. H., McGregor, S., Spence, P., Meehl, G. A., Timmermann, A., Cai, W., Gupta, A. S., McPhaden, M. J., Purich, A., and Santoso, A.: Recent intensification of wind-driven circulation in the Pacific and the ongoing warming hiatus, Nat. Clim. Change, 4, 222-227, 2014.

Gipson, J. M.: El Niño and VLBI Measured Length of Day, in: IVS 2016 General Meeting Proceedings: New Horizons with VGOS, edited by: Behrend, D., Baver, K. D., and Armstrong, K. L., 13-17 March 2016, Johannesburg, South Africa, p. 336, 2016.

Hide, R. and Dickey, J. O.: Earth's Variable Rotation, Science, 253, 629-637, https://doi.org/10.1126/science.253.5020.629, 1991.

Hide, R., Dickey, J., Marcus, S., Rosen, R., and Salstein, D.: Atmospheric angular momentum fluctuations during 1979-1988 simulated by global circulation models, Phys. Chem. Earth, 23, 10891090, https://doi.org/10.1016/S0079-1946(98)00148-7, 1998.

Hide, R., Boggs, D. H., and Dickey, J. O.: Angular momentum fluctuations within the Earth's liquid core and torsional oscillations of the core-mantle system, Geophys. J. Int., 143, 777-786, 2000.

Holme, R. and de Viron, O.: Characterization and implications of intradecadal variations in length of day, Nature, 499, 202-204, 2013.

Huang, H.-P., Sardeshmukh, P. D., and Weickmann, K. M.: The balance of global angular momentum in a long-term atmospheric data set, J. Geophys. Res., 104, 2031-2040, https://doi.org/10.1029/1998JD200068, 1999.

Jeffreys, H.: Causes contributory to the annual variations of latitude, Mon. Weather Rev., 44, 337-337, https://doi.org/10.1175/15200493(1916)44<337b:CCTTAV>2.0.CO;2, 1916.

Ji, X., Neelin, J. D., and Mechoso, C. R.: Baroclinic-to-Barotropic Pathway in El Niño-Southern Oscillation Teleconnections from the Viewpoint of a Barotropic Rossby Wave Source, J. Atmos. Sci., 73, 4989-5002, https://doi.org/10.1175/JAS-D-16-0053.1, 2016.

Johnson, N. C.: How Many ENSO Flavors Can We Distinguish?, J. Climate, 26, 4816-4827, https://doi.org/10.1175/JCLI-D-12$00649.1,2013$.

Kao, H.-Y. and Yu, J.-Y.: Contrasting Eastern-Pacific and Central-Pacific Types of ENSO, J. Climate, 22, 615-632, https://doi.org/10.1175/2008JCLI2309.1, 2009.

Lee, T. and McPhaden, M. J.: Increasing intensity of El Niño in the central-equatorial Pacific, Geophys. Res. Lett., 37, 114603, https://doi.org/10.1029/2010GL044007, 2010.

Lee, T., Hobbs, W. R., Willis, J. K., Halkides, D., Fukumori, I., Armstrong, E. M., Hayashi, A. K., Liu, W. T., Patzert, W., and Wang, O.: Record warming in the South Pacific and western Antarctica associated with the strong centralPacific El Niño in 2009-10, Geophys. Res. Lett., 37, L19704, https://doi.org/10.1029/2010GL044865, 2010.

L'Heureux, M. L., Takahashi, K., Watkins, A. B., Barnston, A. G., Becker, E. J., Di Liberto, T. E., Gamble, F., 
Gottschalck, J., Halpert, M. S., Huang, B., Mosquera-Vásquez, K., and Wittenberg, A. T.: Observing and Predicting the 2015/16 El Niño, B. Am. Meteorol. Soc., 98, 1363-1382, https://doi.org/10.1175/BAMS-D-16-0009.1, 2017.

Marcus, S. L., Chao, Y., Dickey, J., and Gegout, P.: Detection and modeling of nontidal oceanic effects on Earth's rotation rate, Science, 281, 1656-1659, https://doi.org/10.1126/science.281.5383.1656, 1998.

Marcus, S. L., de Viron, O., and Dickey, J. O.: Abrupt atmospheric torque changes and their role in the 1976-1977 climate regime shift, J. Geophys. Res.-Atmos., 116, D03107, https://doi.org/10.1029/2010JD015032, 2011.

Marcus, S. L., Dickey, J. O., Fukumori, I., and de Viron, O.: Detection of the Earth rotation response to a rapid fluctuation of Southern Ocean circulation in November 2009, Geophys. Res. Lett., 39, L04605, https://doi.org/10.1029/2011GL050671, 2012.

Munk, W. H. and MacDonald, G. J. F.: The Rotation of the Earth: A Geophysical Discussion, Cambridge University Press, Cambridge, 1960.

Paek, H., Yu, J.-Y., and Qian, C.: Why were the 2015/16 and 1997/98 Extreme El Niños different?, Geophys. Res. Lett., https://doi.org/10.1002/2016GL071515, in press, 2017.

Palmeiro, F. M., Iza, M., Barriopedro, D., Calvo, N., and GarcíaHerrera, R.: The complex behavior of El Niño winter 2015-2016, Geophys. Res. Lett., https://doi.org/10.1002/2017GL072920, in press, 2017.
Petit, G. and Luzum, B.: IERS Conventions 2010, IERS Technical Note 36, Verlag des Bundesamts für Kartographie und Geodäsie, Frankfurt am Main, 179 pp., 2010.

Ponte, R. M. and Rosen, R. D.: Torques Responsible for Evolution of Atmospheric Angular Momentum during the 1982-83 El Niño, J. Atmos. Sci., 56, 3457-3462, https://doi.org/10.1175/15200469(1999)056<3457:TRFEOA>2.0.CO;2, 1999.

Ponte, R. M., Rosen, R., and Boer, G.: Angular momentum and torques in a simulation of the atmosphere's response to the 1982 83 El Niño, J. Climate, 7, 538-550, 1994.

Ren, H.-L. and Jin, F.-F.: Niño indices for two types of ENSO, Geophys. Res. Lett., 38, L04704, https://doi.org/10.1029/2010GL046031, 2011.

Song, J., Wang, Y., and Tang, J.: A Hiatus of the Greenhouse Effect, Scient. Rep., 6, 33315, https://doi.org/10.1038/srep33315, 2016.

Takahashi, K., Montecinos, A., Goubanova, K., and Dewitte, B.: ENSO regimes: Reinterpreting the canonical and Modoki El Niño, Geophys. Res. Lett., 38, 110704 , https://doi.org/10.1029/2011GL047364, 2011.

van Niekerk, A., Shepherd, T. G., Vosper, S. B., and Webster, S.: Sensitivity of resolved and parametrized surface drag to changes in resolution and parametrization, Q. J. Roy. Meteorol. Soc., 142, 2300-2313, https://doi.org/10.1002/qj.2821, 2016.

Wang, G. and Cai, W.: Climate-change impact on the 20thcentury relationship between the Southern Annular Mode and global mean temperature, Scient. Rep., 3, 2039, https://doi.org/10.1038/srep02039, 2013. 